\title{
EJA MOVIMENTOS SOCIAIS E FORMAÇÃO INICIAL DE EDUCADORES NA UNIVERSIDADE
}

\author{
Edna Castro de Oliveira \\ Elizangela Ribeiro Fraga \\ Tatiana de Santana Vieira ${ }^{(*)}$
}

Tendo em vista a tarefa que a universidade pública é chamada a assumir nos processos de formação de educadores, em diferentes áreas do conhecimento, a investigação presente neste artigo perseguiu como problema uma questão que tem se colocado de forma permanente, e se atualiza no fluxo da oferta semestral do curso de Pedagogia da Universidade Federal do Espírito Santo (UFES): quais as contribuições da disciplina Movimentos Sociais e Educação de Jovens e Adultos (MSEJA) para a formação acadêmica e política dos estudantes? O movimento da pesquisa teve, como objetivos, refletir acerca da formação inicial de educadores na referida disciplina com estudantes do $3^{\circ}$ período, sobre suas concepções sobre a modalidade e da ação dos movimentos sociais, bem como explorar vínculos entre esses segmentos e compreender as razões do envolvimento ou não de estudantes em ações coletivas protagonizadas pelos movimentos sociais, no percurso de 2010, 2012 e 2015 .

A pesquisa, de natureza qualitativa, tomou como inspiração algumas características da pesquisa participante, uma vez que contou com a inserção compartilhada das pesquisadoras no contexto da formação. Como professora e orientandas, essas se assumiram junto aos estudantes no

\footnotetext{
${ }^{(*)}$ Edna C. Oliveira. Possui graduação em Pedagogia pela Universidade Federal do Espírito Santo (UFES, 1974), mestrado em Educação pela UFES (1988) e doutorado em Educação Brasileira pela Universidade Federal Fluminense (UFF, 2005). Atualmente é professora associada da UFES, integra a linha de pesquisa Diversidade e Práticas Educacionais Inclusivas do PPGE/CE/UFES e coordena o Núcleo de Educação de Jovens e Adultos do Centro de Educação e o Núcleo I - PPG-UFES, da rede de pesquisa do Programa Observatório da Educação (Obeduc/Capes). Tem se dedicado à pesquisa na formação de educadores de jovens e adultos, interface com as seguintes áreas: formação, alfabetização, educação do campo, educação profissional, políticas públicas e movimentos sociais. Currículo: <http://lattes.cnpq.br/1029441038069805>.

Elizangela R. Fraga. Graduada em pedagogia. Doutoranda pelo Programa de Pós-graduação em Educação da Universidade Federal do Espírito Santo (PPGE/CE/UFES). Membro do Núcleo I - PPG-UFES, da rede de pesquisa do Programa Observatório da Educação (Obeduc/Capes). Bolsista Capes pelo PPGE/UFES. Currículo: <http://lattes.cnpq.br/7780559822354917>.

Tatiana S. Vieira. Graduada em História pela Universidade Federal do Espírito Santo (UFES). Doutoranda e Mestra em Educação pelo Programa de Pós-graduação em Educação (PPGE/CE/UFES). Membro do Núcleo I - PPG-UFES, da rede de pesquisa do Programa Observatório da Educação (Obeduc/Capes). Currículo: <.http://lattes.cnpq.br/1929672926141322>.
} 
desenvolvimento da prática do Estágio em Docência ${ }^{1}$ nas turmas, o que caracterizou uma ação orquestrada de formação em vários níveis de formação inicial e continuada.

No movimento da pesquisa, as conexões entre movimentos sociais e educação vão se explicitando na medida em que consideramos os desencadeamentos produzidos pela legislação, gestada a partir de movimentos de educadores e pesquisadores no âmbito da sociedade civil, em prol de mudanças nos rumos da educação e do processo de democratização do Estado brasileiro. Nesse sentido, torna-se necessário enfatizar que a proposta vigente para a formação, no Projeto Político Pedagógico (PPP) do curso de Pedagogia da UFES (2010), é resultado de mobilizações e lutas no âmbito de instâncias da sociedade civil organizada, entre elas a Associação Nacional pela Formação de Professores (Anfope), que defende uma organização curricular e institucional para a formação de professores com o seguinte foco:

A formação para o humano, forma de manifestação da educação omnilateral dos homens; - a docência como base de formação profissional; - o trabalho pedagógico como foco formativo; a sólida formação teórica em todas as atividades curriculares; - a ampla formação cultural; - a criação de experiências curriculares que permitam o contato dos alunos com a realidade da escola básica, desde o início do curso; a incorporação da pesquisa como princípio de formação; a possibilidade de vivência, pelos alunos, de formas de gestão democrática; o desenvolvimento do compromisso social e político da docência [...] (UFES, 2010, p. 2).

Observa-se, a partir desse foco que, desde a instituição das Diretrizes Curriculares Nacionais para o Curso de Pedagogia (DCNP) pelo Parecer CNE/CP 05/2005, a ênfase da formação do curso, em nível nacional e, em específico, no da UFES, ganha centralidade na formação do pedagogo, tendo a docência como base da formação de educadores para atuar nas séries iniciais do ensino fundamental. A implementação das Diretrizes acirrou o debate sobre o conteúdo da formação do pedagogo e a do especialista, "para se repensar a formação dos supervisores, administradores e orientadores educacionais de forma integrada, e sua inserção em ações conjuntas na prática escolar" (PATUZZO, 2014, p. 31). Com a extinção das habilitações ofertadas pela UFES, durante a implementação das DCNP, o conteúdo da formação voltado para a educação de jovens e adultos tornou-se de certa forma residual, ${ }^{2}$ o que se conformou na grade curricular, a partir de 2006, na manutenção de apenas duas disciplinas, oriundas da Habilitação em EJA, ofertadas respectivamente no yerceiro e no sétimo período.

\footnotetext{
${ }^{1}$ Disciplina obrigatória ofertada pelo Programa de Pós-graduação em Educação (PPGE/CE/UFES) aos bolsistas de Mestrado e Doutorado.

${ }^{2}$ O currículo do curso ofertava três habilitações: educação infantil, educação especial e educação de jovens e adultos A habilitação em EJA foi uma das últimas a ser ofertada a partir de 2001, pelo curso de Pedagogia, envolvendo três disciplinas teóricas e uma de estágio, tendo a disciplina MSEJA como um de seus componentes.
} 
Em 2015, o Conselho Nacional de Educação aprovou o Parecer e a Resolução CNE/CP 02/2015 que definiram as Diretrizes Curriculares Nacionais para a formação inicial e continuada dos professores da educação básica. As Diretrizes orientam os sistemas estaduais e municipais a atuarem de forma orgânica com as instituições formadoras, buscando promover formação inicial e continuada dos profissionais do magistério, considerando as especificidades das diferentes modalidades da educação básica, tendo em vista a qualificação do trabalho docente.

Essa atualização da tarefa de formação da universidade nos permite retomar o sentido deste estudo sobre as contribuições da oferta da disciplina em foco, a partir da reflexão dos estudantes, uma vez que essa busca explorar a formação política e acadêmica de forma integrada. Os entrelaçamentos que se vão produzindo reafirmam a necessidade de atentar para a formação inicial de educadores na modalidade de educação de jovens e adultos no curso de Pedagogia da UFES bem como para o papel da universidade na formação acadêmica e política dos sujeitos.

\section{EJA E MOVIMENTOS SOCIAIS NO CURSO DE PEDAGOGIA NA UFES}

O Centro Pedagógico da UFES, criado em 1968, no auge do período da ditadura civilmilitar, constituiu unidade própria de ensino profissional e pesquisa aplicada aos estudos pedagógicos. Guarda, assim, um percurso de organização curricular que não deixa de navegar nas ondas da formação inicial de professores, em relação estreita com as demandas de um Estado autoritário e suas regulações. Assim, sem a pretensão de historicizar o percurso de mudanças curriculares pelas quais passava o curso de Pedagogia na UFES no contexto da implementação das DCNP, consideramos importante ressaltar que a atual oferta do curso observa o Parecer CNE/CP 05/2005 que institui as DCNP e destina-se à formação de professores para exercer funções de:

- Magistério na educação infantil e nos anos iniciais do ensino fundamental, nos cursos de ensino médio na modalidade normal, de educação profissional, na área de serviços;

- Apoio escolar e em outras áreas nas quais sejam previstos conhecimentos pedagógicos;

- Gestores educacionais, o que compreende participação na organização e gestão de sistemas e instituições de ensino, englobando: planejamento, execução, coordenação, acompanhamento e avaliação de tarefas próprias do setor da educação; planejamento, execução, coordenação, acompanhamento e avaliação de projetos e experiências educativas não-escolares; 
- Formação para produção e difusão do conhecimento científico e tecnológico do campo educacional em contextos escolares e não-escolares (UFES, 2010).

Nesse contexto, o perfil do profissional em formação baseia-se no pressuposto de que o Pedagogo deve assumir postura profissional ética pautada na responsabilidade social para com a construção de uma sociedade includente, justa e solidária, no exercício da docência, gestão, produção e difusão de conhecimentos. O Parecer destaca, ainda, que "o curso de Pedagogia deverá contemplar [...] a compreensão dos processos de formação humana e das lutas históricas nas quais se incluem as dos professores, por meio de movimentos sociais" (CNE/CP 05/2005, p. 12).

Como possibilidade de responder a esse perfil de formação, a disciplina MSEJA propõe como objetivo geral explorar as relações entre educação, sociedade civil e Estado a partir do estudo das concepções dos movimentos sociais e da educação de jovens e adultos e suas contribuições para a atual configuração da EJA no Brasil. Entre os objetivos específicos busca: estudar as concepções teórico-metodológicas da educação popular e EJA no Brasil e seu legado para este campo de conhecimento; analisar as relações movimentos sociais e Estado; conhecer as práticas de alguns movimentos sociais e suas demandas de EJA, bem como explorar as diversidades dos sujeitos da EJA e suas especificidades socioculturais em nível local e global.

Em diálogo com os objetivos, a disciplina aborda como principais temas: trajetória e memória da EJA e movimentos sociais (MS); tensões e desafios na formulação, implementação e consolidação das políticas de EJA nos planos global e local; a educação como direito humano universal, direitos humanos e movimentos sociais no Brasil; e os sentidos da EJA como direito e como educação ao longo da vida: aspectos legais e dilemas.

Durante o processo de atuação em sala de aula/investigação, percebemos que no início do período do curso, na disciplina MSEJA, havia poucos estudantes que participavam de ações referentes à educação de jovens e adultos e/ou de movimentos sociais. Porém, com o desenvolvimento do trabalho político-pedagógico no decorrer dos períodos (estudo, debates, seminários, palestras, pesquisa de campo...) foi possível constatar uma aproximação/envolvimento maior de estudantes em diversos espaços/tempos, dentre os quais destacamos: o Fórum de EJA/ES; o Núcleo de Educação de Jovens e Adultos (NEJA/CE/UFES); os Encontros Estaduais e Regionais dos Sem Terrinha MST/ES; o Comitê Estadual de Educação do Campo do Espírito Santo (Comeces); os processos de criação do curso de Licenciatura em Educação do Campo (Procampo); o movimento estudantil; a participação em marcha com os catadores de material reciclável; as turmas do curso de Pedagogia da Terra; o movimento de greve na UFES; as visitas e estágios em 
escolas de assentamentos de reforma agrária MST; as palestras, bancas e seminários que abordam a temática.

Esse envolvimento foi sendo produzido pelos grupos provocados a conhecer os movimentos, abordar e estudar outras temáticas, como parte da metodologia da disciplina em um exercício de pesquisa em trabalho de campo. A partir de um espaço/tempo os grupos relacionam a discussão teórica com o exercício de pesquisa in loco. Esse movimento é vital para a formação dos estudantes, pois tem sido evidenciado que, para muitos, é o primeiro contato com experiências de EJA e/ou de movimentos sociais, o que colabora para que estabeleçam relações entre os conteúdos estudados em sala de aula.

A disciplina enfrenta muitos desafios na formação de educadores, entre eles merece destaque a abordagem de sua temática (MS e EJA) no contexto do curso, uma vez que este prioriza em sua organização curricular a formação profissional e pedagógica voltada em grande parte para a educação escolar básica. Considerando que a EJA tem como uma de suas matrizes a educação popular, como um campo de conhecimento gestado no âmbito dos movimentos sociais, coloca-se para a disciplina o desafio de não perder de vista essa ênfase, uma vez que esta matriz se constitui fundante para consolidar a formação política e acadêmica dos estudantes, em conformidade com a perspectiva de Paulo Freire (2007) de que a ação educativa é também ação política.

\section{A DIFÍCIL TAREFA DE ENTRELAÇAR O CONTEÚDO DA FORMAÇÃO PROPOSTA: EJA E MOVIMENTOS SOCIAIS}

Em vista da configuração atual do capitalismo tardio, e num contexto de crise estrutural em que vigora um "modelo de desenvolvimento sustentado numa concepção de mundo baseada na sociedade mercantil” (AGUIAR, BOLLMANN, 2011, p. 62), o Brasil e o mundo vivem um momento de efervescência de várias mobilizações coletivas que colocam em questão o "caráter dual e contraditório dos movimentos sociais, ou seja, de ruptura ou de manutenção do status quo" (AGUIAR, BOLLMANN, 2011, p. 62).

Nesse cenário complexo importa refletir sobre a difícil tarefa de conceituar os movimentos sociais, a partir de estudos desenvolvidos por Gohn (2010a; 2010b), Aguiar e Bollmann (2011), entre outros, buscando explorar a complexidade do conceito. Afinal, o que são movimentos sociais e, em específico, os movimentos sociais em educação? Gohn (2010b, p. 14) nos leva a refletir sobre a questão, quando toma como uma das referências de compreensão da atual configuração dos movimentos sociais, a ideia de que: 
Um movimento social é sempre expressão de uma ação coletiva e decorre de uma luta sociopolítica, econômica ou cultural. Usualmente [...] tem [como] constituintes: demandas que configuram sua identidade; adversários e aliados; bases, lideranças e assessorias - que se organizam em articuladores e articulações e formam redes de mobilizações; [...] e culturas próprias nas formas como sustentam e encaminham suas reivindicações. [...] Os movimentos sociais têm nos direitos a fonte de inspiração para a construção de sua identidade. (Grifos nossos).

Gohn (2010a) sustenta, ainda, que os movimentos sociais são fundamentados por um projeto de vida e de sociedade; ressignificam os ideais clássicos de igualdade, fraternidade e liberdade com a tematização da justiça social, solidariedade e autonomia; atuam como movimentos de fiscalização e controle das políticas públicas atuando em fóruns, conselhos, câmaras, em escala local, regional e nacional impulsionados pelas alterações das relações entre Estado e sociedade civil, uma vez que as políticas sociais institucionalizadas buscam a coesão e o controle social pela mediação de políticas públicas de inclusão social.

Os movimentos sociais têm caráter educativo e de aprendizagem para seus protagonistas (GOHN, 2010a). No mesmo sentido, Gramsci (s/d) destacou a importância da formação de lideranças na classe trabalhadora para atuarem na luta dos trabalhadores, como intelectuais orgânicos. Essa ideia é ressignificada na dimensão da formação política dos militantes pelos movimentos sociais. Bogo (2008, p. 181) destaca a relevância da formação política como mecanismo de motivação para ação consciente em prol das transformações sociais. Para o autor:

[...] não basta que eles [os militantes] tenham um nível elevado de informações e conhecimentos, é preciso que transformem esse conhecimento em diretrizes que se combinem com os "desejos e motivações" das massas nas ações concretas. Fora disso todo conhecimento político é inútil.

Aguiar e Bollmann (2011), ao se fundamentarem em autores como Sapelli (2008) e Domingues (2007), problematizam a ideia de ação coletiva no que se refere à concepção e identidade dos movimentos sociais. Para esses autores (AGUIAR; BOLLMANN, 2011, p. 63) vários são os elementos que contribuem para identificar um movimento social, entre eles "a consciência da situação de opressão relacionada à perspectiva de reprodução ou de transformação social", entendendo que "para além da unidade de um grupo social em torno de um mesmo objetivo [...] um movimento social tem uma perspectiva de ação que pode ser na direção da manutenção do status quo da sociedade". O que significa dizer, segundo os autores, que nem sempre "movimento social é sinônimo de ação coletiva transformadora ou revolucionária”. 
Uma outra conexão necessária nas relações entre movimentos sociais e educação diz respeito ao conteúdo da disciplina no imbricamento entre sociedade civil e Estado. A mobilização produzida pelos setores educativos quando passam a reclamar maior "participação no âmbito político-educativo, ganha corpo em movimentos de criação de entidades que assumem um papel fundamental no processo de abertura política, no final da década de 1970 e início de 1980" (AGUIAR; BOLLMANN, 2011, p. 70).

O movimento em prol da democratização da sociedade e educação brasileiras tem, nos militantes e profissionais da educação - liderado pela Anfope e por pesquisadores da Associação Nacional de Pós-Graduação e Pesquisa em Educação (ANPEd) -, bem como nos profissionais de outras instâncias políticas como organizações e confederações sindicais e científicas, uma confluência de forças, "comprometidas com o futuro das políticas educativas no país". (AGUIAR; BOLLMANN, 2011, p. 71). Importa destacar que, da confluência dessas organizações surge o Fórum de Educação na Constituinte, que a partir dos anos 1990 passa a se chamar Fórum Nacional em Defesa da Escola Pública (2001). "Esse Fórum, integrando a articulação de movimentos e organizações da sociedade civil liderou movimentos pela educação pública gratuita como direito de todos e dever do estado" (AGUIAR; BOLLMANN, 2011, p. 78). Suas manifestações deixaram marcas em diferentes momentos da política educacional brasileira - "no processo constituinte (1986-1988), na tramitação da LDB (Lei 9.394/06) (1988-1996) e na convocação dos Congressos Nacionais de Educação (CONEDs) onde tem origem a elaboração do Plano Nacional de Educação Proposta da Sociedade Brasileira" (AGUIAR; BOLLMANN, 2011, p. 78), debate que ganha corpo na disciplina, pela atualização e discussão do movimento do Plano Nacional de Educação (PNE), 2014-2024.

No âmbito da educação de jovens e adultos, as lutas empreendidas impõem a seus militantes o desafio de se assumirem como protagonistas de um movimento social que atualmente se configura nos Fóruns de Educação de Jovens e Adultos do Brasil, presentes em todo o território nacional, com seus momentos de ascensão e recuos frente à atual lógica da sociedade global. Os avanços no campo da educação de jovens e adultos, reconhecidos como fruto da construção coletiva da militância, enfrentam os riscos de esvaziamento, desqualificação e reafirmação da negação de direitos conquistados a partir da Constituição de 1988, à semelhança de outras conquistas nas políticas educacionais. Essas reflexões são colocadas em foco no sentido de provocar a ação e envolvimento dos estudantes nas discussões.

O debate sobre o que é a modalidade, e o que conhecem sobre a modalidade integra parte do conteúdo em que polêmicas, como a da idade mínima emerge como uma das questões de interesse. 
A legislação vigente, em especial o Parecer CNE/CEB 11/2000 e a Resolução CNE/CEB n. 03/2010, são então explorados. A Resolução CNE/CEB 03/2010, nos seus arts. $5^{\circ}$ e $6^{\circ}$ institui a “idade mínima de 15 anos para os cursos de EJA e realização de exames de conclusão de EJA no Ensino Fundamental" e 18 anos para o Ensino Médio. Já o Parecer CNE/CEB 11/2000 (BRASIL, 2000) reafirma a educação de jovens e adultos como uma modalidade da educação básica voltada para escolarização de sujeitos que não tiveram seu processo de escolarização concluído na chamada idade própria/ano escolar. Ao explorar as funções da EJA - reparadora, equalizadora e qualificadora - sustenta que as formas de organização curricular e de oferta da EJA como política pública tem sua aposta na formação ao longo da vida e como ponto fundante para a formação humana integral dos sujeitos.

A partir das discussões acima, retomamos a difícil tarefa, no movimento da disciplina, de estabelecer diálogos (FREIRE, 1996) entre movimentos sociais e EJA na formação inicial no curso de Pedagogia, buscando construir sentido dessa formação. O que nos fez, em determinados momentos, priorizar mais um ou outro componente, dependendo da mobilização das turmas e de seus interesses, o que consideramos uma das limitações encontradas no processo.

\section{ABORDAGEM METODOLÓGICA}

A opção metodológica assumida no processo, de natureza qualitativa, teve como inspiração as reflexões de Boterf (1999), quando discute sobre as várias formas de fazer pesquisa participante. Destaca o autor como uma das características da pesquisa participante as formas de trabalho pedagógico:

[...] "incitativa" que envolve "as disposições dos indivíduos no desenvolvimento do aprendizado pessoal, [e] apropriativa" centrada na inserção social do indivíduo, mediação pela qual se exerce o ato de formação como ponto de partida e chegada da apropriação cognitiva. (BOTERF, 1999, p. 74).

Desse modo, o processo de investigação foi mediado pela participação das orientandas com a professora no planejamento e durante as aulas da disciplina MSEJA. Esse movimento produziu diálogos entre teoria e prática a partir das experiências compartilhadas com os estudantes de Pedagogia e de Geografia, nos anos de 2010, 2012 e 2015.

Para coleta e análise de dados, a pesquisa lançou mão de instrumentos como observação participante durante as aulas, aplicou questionários no início dos semestres letivos para diagnóstico das turmas, com relação ao conhecimento e envolvimento dos estudantes em movimentos sociais, assim como aproximações com a educação de jovens e adultos. Também foram realizadas 
entrevistas semiestruturadas com graduandos após o final da disciplina com o objetivo de conhecer, junto aos estudantes, em que a disciplina contribuiu com a formação política e acadêmica dos mesmos.

\section{Contribuições da formação inicial de educadores na interface dos segmentos EJA e Movimentos Sociais}

Nesta seção apresentamos algumas análises da escuta que fizemos, a partir das entrevistas, com os graduandos do curso de Pedagogia de turmas diferentes e da Geografia, com os quais trabalhamos entre 2010 a 2012 e em 2015. Essa escuta foi organizada partindo de um roteiro de entrevista semiestruturado com questões que envolviam a temática e a contribuição da disciplina MSEJA. Neste trabalho destacaremos a escuta de quatro graduandos do curso de Pedagogia e um do curso de Geografia ${ }^{3}$ da UFES, os quais serão chamados de João, José, Francisco, Maria e Ana ${ }^{4}$.

A questão inicial envolveu as experiências de EJA dos graduandos antes de cursarem a disciplina. Maria atuava como estagiária em Pedagogia no Instituto Federal do Espírito Santo (IFES) e sua experiência com a EJA foi como apoio em atividades dos cursos do Programa Nacional de Integração da Educação Profissional com a Educação Básica na Modalidade de Educação de Jovens e Adultos (Proeja).

João relatou que não foi aluno da EJA, mas por meio do trabalho na Secretaria de Educação de Vitória (SEME), onde atuava na área de mobilização estudantil por cerca de quatro anos, período no qual foi estagiário de ensino médio, conheceu educandos de EJA que eram líderes de turma nas escolas, e pôde observar "algumas especificidades existentes na modalidade".

Francisco conheceu a modalidade por meio de uma breve experiência como professor substituto na EJA. Ana e José têm experiência como docentes. Entretanto, Ana atuou no período noturno, mas não com a modalidade de EJA. José tem licenciatura na área de ciências humanas e atua como docente há alguns anos. Resgatou sua experiência como professor de história no interior do estado de Minas Gerais, no final da década de 1990, para turmas de EJA. Destacou a grande quantidade de educandos por sala, a dificuldade em conseguir materiais didáticos (mesmo que não fossem específicos para a EJA) e os desafios em desenvolver um trabalho com turmas heterogêneas:

Havia alunos desde 14 anos até 40, 50, 60 [anos]. Eu dividia a turma por grupos, dava a tarefa e acompanhava os grupos nas tarefas, foi a maneira que eu encontrei de dinamizar as atividades. Eles debatiam, elaboravam questões, respondiam... foi a experiência que eu tive.

\footnotetext{
${ }^{3}$ Esse aluno, embora finalista, passou a frequentar a disciplina como optativa.

${ }^{4}$ Optou-se pela utilização de nomes fictícios para resguardar a identidade dos estudantes.
} 
No que tange à experiência com movimentos sociais, José participou ativamente do movimento estudantil desde o ensino fundamental:

Tudo aquilo que vinha escrito em livros do que é bacana, o [colégio] São Vicente tinha, naquela época, mas era uma participação que nós alunos provocávamos, não era uma participação que o diretor, a escola, a pedagoga promovia [...].

Em sua fala, o protagonismo dos educandos é um fator marcante na organização e desenvolvimento das ações do grêmio estudantil. Em suas palavras, "um verdadeiro protagonismo estudantil juvenil". Essa experiência foi ampliada com a participação em outros coletivos, como o movimento de juventude e a política. Além desses espaços, José tem uma ligação orgânica com o samba na Grande Vitória, região metropolitana do Espírito Santo:

Eu sou ligado ao samba antes da escola, antes da juventude. Nasci no samba, sou do samba, minha família inteira [foi] criada no samba, então também participo do movimento social. Não sei se posso considerar [o samba] movimento social. Mas movimento cultural que é o samba, mas não deixa de estar atrelado porque os movimentos sociais, quando tem festa, chamam o samba pra agitar, então o samba está ligado, sim, aos movimentos sociais. Os artistas populares que tem dentro do samba estão nos movimentos sociais, não todos, por falta de conhecimento, mas a maioria.

Nesse trecho apresentado acima, José elabora um questionamento em torno do conceito de movimentos sociais. Embora na continuidade de sua fala ele mesmo estabeleça a distinção entre movimentos sociais e movimentos culturais. Não deixa de marcar as trocas entre formas de organização social. Sobre sua concepção de movimentos sociais antes de cursar a disciplina diz:

Eu pensava que era um grupo de pessoas “eu defendo os negros, eu defendo as mulheres", eu pensava que eram grupos que discutiam, mas não tinham essas organizações que têm, por exemplo, Conselho Municipal do Direito disso... daquilo [...] pra mim não era tão amplo e não tinha histórico e na disciplina eu pude perceber que tem histórico, tem relevância.

João também descreve como o conceito de movimentos sociais foi sendo elaborado por ele no decorrer da disciplina e relaciona a forma de organização que conhece com a noção de direito e cidadania:

Eu sabia, via os movimentos sociais, mas não sabia por essa designação. Eu via os movimentos dos sindicatos, desfiadeiras de siris, mas não conhecia por esse nome: "movimentos sociais". Sabia que não era uma questão de excluídos, porque de alguma maneira eles estavam no meio do negócio, mas eles queriam um pouco mais de visibilidade para alcançar direitos de cidadãos. Porque se eles fossem excluídos eles não saberiam estar ali, pelo menos é a minha compreensão. Eu via em São Pedro, na época surgiu um movimento lá, que ainda existe até hoje: Mulheres Unidade de São Pedro, eu achei o nome esquisito MUSP, mas aí eu fui ver a intenção delas e achei interessante, mas eu não sabia o que era isso, sabia apenas que era um grupo organizado para requerer direitos que não estavam recebendo. 
Maria demonstra uma relação diversa dos estudantes anteriores sobre a compreensão dos movimentos sociais: relacionava-os à baderna e a "um lugar onde eu não deveria estar". Nasceu e cresceu em uma cidade do interior do estado, onde nunca tinha discutido ou lido sobre as questões teóricas acerca dos movimentos sociais clássicos. Segundo a estudante, no interior, esse movimento não é incentivado. Ressalta, ainda, que cursar a disciplina e a experiência com a EJA no IFES transformou completamente seu modo de pensar sobre os movimentos sociais e conclui: "hoje, quando vejo os movimentos, posso confrontar minha maneira anterior que foi mudada. Abriu para compreender questões teóricas de outras disciplinas [...] o curso sem essa disciplina dá condição muito restrita”.

Ana destaca como a disciplina incentivou na conceituação de movimentos sociais e, além disso, foi o elo para que conhecesse uma experiência:

[...] E também durante as aulas dela (da professora), eu lembro que ela pediu que a gente escolhesse um movimento social para trazer à tona, e como eu trabalhava com a obra de Sebastião Salgado e ele teve com o MST, eu andei pesquisando sobre o movimento sem terra para poder entender o que era. Então, foi um conhecimento que eu adquiri na disciplina [...]. A disciplina mudou completamente a forma de ver as coisas. A minha relação com o Movimento Sem Terra é outra. Eu tinha um pensamento e agora tenho outro. Com o movimento que eu estudei, LGBT, também é completamente outro, então foi um divisor de água e ela contribuiu na parte que trata da EJA.

Diferente dos demais entrevistados, Francisco participa de movimentos sociais, a partir de uma experiência com os movimentos sociais do campo,

Atualmente, faço parte de movimento do campo, a partir de um trabalho que eu faço na geografia com as comunidades tradicionais. Nos movimentos sociais do campo está a pauta da educação que é bastante reivindicada e atualmente está surgindo com bastante força que é a educação do campo. Eu faço parte de dois vestibulares alternativos, como voluntário.

Após discorrerem sobre a conceituação da temática da disciplina, os estudantes destacaram o papel de MSEJA na formação de professores e pedagogos e sua contextualização com outras disciplinas. João estabeleceu laços com a disciplina sociologia da educação, destacando o conceito de ideologia:

Em 2011, quando fiz a disciplina na área de sociologia, tive acesso a textos relacionados à área da educação nas empresas, a questão da ideologia dessa educação. Quando eu fiz a disciplina de movimentos sociais eu fui ver a consequência dessas ações, aí pra mim fechou o círculo. Eu comecei a ver o desdobramento das ações que a gente vê, mas não enxerga. Pra mim, nesse momento, eu comecei a ver os resultados dessas questões ideológicas que são colocadas e a gente nem percebe que estão ocorrendo. 
José, por sua vez compreendeu a disciplina como um elemento de fortalecimento da prática de militantes e pontuou o referencial teórico, especialmente os textos de Paulo Freire e acrescenta:

Eu acho que é uma das poucas disciplinas na Pedagogia que discute o profissional e as relações sociais [...] contribuiu muito pra mim lá no meu trabalho com jovens, para nos organizarmos melhor, de se "infiltrar" nos espaços públicos; onde o poder público abria porta a gente ia, acho que foi a partir daí, com as leituras dos textos [...] eu peguei a disciplina para minha prática, para avaliar a minha prática e como poderia contribuir e isso foi muito proveitoso pra mim [...].

Além das relações com os movimentos sociais, os graduandos também problematizaram a formação de educadores para a EJA. O estudante João tinha como expectativa o foco na discussão da EJA e reflete:

Talvez seja para inserir, dentro da mente dos alunos, as consequências das pessoas não ter uma visão mais geral dos processos educacionais, porque as consequências de um... tem questões que dizem respeito à família, tem questões sociais, mas se o professor não for um professor que dê uma motivação para seus alunos, se ficar satisfeito apenas de receber seu salário no fim do mês, o aluno não vai.

José discutiu a questão da EJA para além da escolarização, e destacou a contribuição das pessoas mais antigas da comunidade para preservação da cultura local. Observou que esse processo de conscientização foi resultado da organização do grupo a partir das ações desencadeadas pelos estudos na disciplina:

A partir do samba, a gente começava a discutir porque que a escola de samba hoje dá mais valor a quem não é morador do morro, do que quem é fruto dessa escola, por que o avô passou ali, o avô fundou, carregou a lajota que construiu a sede, por que essa escola não dá mais valor a essas pratas da casa, a esses frutos da casa? [...] por que a escola não valoriza os artistas populares que tem dentro da comunidade? [...] é um movimento cultural que tem as questões sociais, porque tem as diferenças, tem as divergências e isso tudo nos provocou a nos constituir um grupo de fato e fazermos um centro de memória pra discutir isso [...].

É evidente nas falas a contribuição da disciplina para a formação política e acadêmica dos estudantes, nos planos individual e coletivo, como observamos no relato acima, em que José explana sobre sua experiência na comunidade onde mora e atua. $\mathrm{O}$ estudante João descreve esse movimento em sua turma como apresentado a seguir:

Teve a passeata, eu não fui. Teve alguns que foram, acharam interessante, tiraram fotos... saíram a contragosto porque tinha que fazer um..., mas acharam interessante terem ido, observado... na realidade. Tem alguns alunos que têm esses problemas como se fossem uma cabeça de bacalhau: sabem que existem, mas nunca viram! Então, quando foram nos espaços, associação de catadores, passeatas, em ambientes que não eram comuns deles, eles começaram a perceber que existe um mundo estranho para eles, que eles não entendem, porque a maioria da turma é de adolescentes. Então, eles estão naquele período em que estão sendo cuidados por 
papai e mamãe, arranjar um estágio é o céu... Então eles começaram a ver que têm coisas muito além do que eles estavam vendo até aquele momento, pra eles uma pessoa que está na rua é porque não quer trabalhar, uma pessoa que está morando na rua... Eu fiz trabalho dos moradores de rua, são pessoas em situação de rua. Como eu já tinha lido e pesquisado, eu consegui entender o processo [...] Essas questões foram enchendo os olhos de alguns, eles foram vendo a questão econômica, a perda de emprego, a falta de uma qualificação, não ter a casa própria [...].

O cenário da turma de João e de si próprio pôde ser observado nas demais turmas trabalhadas. O conhecimento ainda incipiente sobre a EJA e movimentos sociais entre os estudantes do curso de Pedagogia da UFES constitui um ponto que merece atenção na formação inicial dos profissionais da área de educação.

Francisco apresenta uma reflexão importante, construída no decorrer da disciplina de MSEJA. Ele demonstrou que conseguiu transpor a visão estereotipada sobre a EJA e avançou na construção de um pensamento que compreende a EJA como uma modalidade da educação básica preocupada com a formação de seus sujeitos.

Na metade do ano passado eu fiz uma formação continuada em EJA. Era um curso de extensão de uma faculdade particular da grande Vitória. Por ter me interessado pela temática de EJA. A experiência que eu tive ao fazer essa formação foi bastante intrigante, porque em um mês me explicaram tudo o que era a EJA, o que se propunha, quem eram os seus sujeitos, mas daquela forma muito simplista e muitas vezes do que é contado pelo Estado. [...] o que eu estudei na disciplina [...] foi bastante esclarecedor, veio mesmo para desconstruir aquele imaginário e mostrar que o público da EJA é muito mais amplo, que a modalidade requer várias características para continuar existindo e para ter sucesso e não simplesmente de qualquer jeito, em qualquer escola, em qualquer horário, não dessa forma, mas de uma forma continuada mesmo. Porque às vezes a gente pensa na EJA de uma forma supletiva mesmo: à noite [...] e a EJA é muito mais do que recuperar o tempo perdido, mas o investimento na formação, na educação.

Ana refletiu também sobre a característica dos seus colegas de classe, identificando neles alguns elementos geralmente associados aos sujeitos da EJA, tais como a dificuldade de leitura e interpretação de textos. Para além da EJA, essas questões estão presentes nas discussões em torno da educação ofertada no sistema público de ensino. Na transição da educação básica para o ensino superior, a aluna problematiza a ação da universidade na inclusão e desenvolvimento de políticas afirmativas, tais como as cotas:

[...] Eu comecei a me incomodar com os alunos da minha sala, que eles não sabiam de muita coisa, eles não sabiam, na hora de ler um texto eles não conseguiam entender e comecei a ver porque eles eram assim. E eu vi que a maioria deles vem de escola pública. Eu comecei a pesquisar: a UFES abre as portas para os alunos cotistas que vêm da escola pública e a 
assistência que ela disponibiliza é uma assistência financeira. O auxílio permanência também é da parte financeira. O apoio pedagógico que na verdade tá na lei do aluno cotista, não é feito. Então eu comecei a me incomodar com isso, então eu fiz um projeto de pesquisa e apresentei para a professora falando com ela que eu tinha interesse em trabalhar nisso.

A aluna segue sua reflexão destacando a relevância da disciplina. Ela opta por distinguir as duas temáticas. Sobre Movimentos Sociais, destaca que a aproximação amplia a visão sobre eles, em muitos casos, restrita à imagem negativa divulgada pela mídia de massa. Quanto à EJA, sugere uma disciplina específica para tratar dessa modalidade, com a argumentação de que a prática se distingue das discussões teóricas, em suas palavras a disciplina "é importante porque a gente conhece a realidade, mas deveria ser maior (com mais tempo) pra gente fazer mais, conhecer melhor e poder contribuir mais com a educação de jovens e adultos". A fala de Francisco contrapõe-se a essa ideia. Para ele:

Essa junção com os movimentos sociais, que a meu ver a disciplina tem, de discutir a EJA a partir dos movimentos sociais foi uma coisa nova que eu não vi nem nas disciplinas de ciências sociais. Eu acho fundamental, porque você discute proposta para além do Estado e para além do capital e, muitas vezes, a gente fica atrelada e essa discussão [que] sempre vinha de quem está em cima, não se discute a educação de quem está na base, na ponta mesmo. Por isso, foi bastante revigorante, e hoje é o que a gente está precisando, da base mesmo, de quem realmente faz a educação... discutir. Agora mesmo a gente acompanhou a ocupação que teve na Sedu e no Rio de Janeiro, os professores estão na luta e não estão tendo visibilidade na mídia e noutros estados esse sucateamento da educação e do sistema educacional. E realmente foi revigorante essa disciplina nesse momento. Acho que a disciplina está no caminho certo, tanto da tomada dos textos quanto das avaliações. A avaliação que é feita de forma contínua durante o curso.

A fala dos dois alunos apresenta pontos de vista distintos: enquanto Ana acredita que a separação entre as duas temáticas possibilitaria o aprofundamento teórico e prático tanto no campo dos movimentos sociais quanto na EJA, Francisco defende que o diálogo entre as duas áreas é de extrema importância para a compreensão da complexidade social, política e econômica que envolve a educação de jovens e adultos.

Corroboramos a ideia de que não devemos discutir a EJA de forma isolada dos movimentos sociais, no entanto consideramos que o tempo destinado a essa dinâmica (60 horas) é insuficiente para que possamos promover estudos e aprofundamentos teóricos e práticos que envolvam as duas temáticas, de forma orgânica, na formação inicial de educadores de EJA. 


\section{CONSIDERAÇÕES FINAIS}

Tendo em vista a questão de investigação proposta, cabe-nos reunir algumas sínteses. Os entrelaçamentos evidenciados entre os movimentos sociais e a educação, explicitados pela ação política de profissionais e militantes da educação, em defesa da sociedade e da educação brasileiras, indicam a relevância desse conteúdo na formação. É possível afirmar, a partir da escuta e análises das concepções e experiências dos estudantes, ainda iniciais, com movimentos sociais e com a EJA, que a disciplina vem trazendo sua contribuição para a formação política e acadêmica, promovendo o alargamento e mudança de concepções.

No entanto, as análises apontam a necessidade de estabelecer relações dialógicas entre a prática social, os conhecimentos trazidos da experiência de participação dos estudantes, bem como entre as bases do conhecimento popular e conhecimento científico, como elementos da formação ressignificando, assim, saberes teóricos e práticos historicamente construídos. Há necessidade de reflexão em torno do lugar restrito conferido às discussões teórico-práticas e político-pedagógicas de temas ligados à educação de jovens e adultos e aos movimentos sociais, articulados na disciplina em foco, conforme o perfil previsto pelas DCNP.

Embora a discussão em torno da EJA e dos movimentos sociais ainda precise ser ampliada nos currículos do curso de Pedagogia e de demais licenciaturas, a pesquisa evidenciou que no processo de formação da universidade os estudantes socializam suas vivências, estudam sobre a realidade sociopolítica em que vivem, discutem sobre os caminhos que serão trilhados por eles, se apropriam de conhecimentos técnicos, científicos e clássicos, necessários para uma atuação consciente nas discussões coletivas dos rumos da sociedade e das possibilidades de mudanças.

Observa-se, ainda, que a disciplina MSEJA tem sido lugar de incentivo à mobilização e participação dos estudantes em outros espaços de formação política na universidade, como Diretórios e Centros Acadêmicos, por exemplo, para a formação dos graduandos em Pedagogia e de outras licenciaturas.

A disciplina enfrenta desafios na integração com outras disciplinas, no sentido de promoverem diálogos com e na prática social no processo de formação de educadores. Embora se tenha a perspectiva de atuação do egresso em espaços não escolares, a centralidade da atuação do pedagogo para atuar na escola básica e, portanto, com o processo de escolarização, acaba, de modo geral, por não explorar com a devida potencialidade outros espaços e tempos formativos, que os movimentos sociais e a EJA promovem, para além da escola. 
Os resultados afirmam, assim, a necessidade de ampliação e fortalecimento do debate na formação de educadores, ao tempo em que apontam o desafio de se promover, no curso de Pedagogia, espaços de maior interlocução com as ações desencadeadas pelos movimentos e possibilitar o contato com experiências e práticas de EJA no âmbito do poder público e/ou da sociedade civil organizada, tendo como perspectiva produzir contribuições para a formação política e acadêmica.

\section{REFERÊNCIAS}

AGUIAR, Letícia Carneiro, BOLLMANN, Maria da Graça Nóbrega. Movimentos sociais em educação e suas contribuições à política educacional brasileira. In: TEODORO, Antônio, JEZINE, Edineide. (Org.). Movimentos sociais e educação de adultos na Ibero-América. Lutas e desafios. Brasília: Liber Livro, 2011. p. 61-80.

BOGO, Ademar. Identidade e luta de classes. São Paulo: Expressão Popular, 2008.

BOTERF, Guy Le. Pesquisa participante: propostas e reflexões metodológicas. In: BRANDÃO, Carlos Rodrigues. (Org.). Repensando a pesquisa participante. São Paulo: Brasiliense, 1985.

BRASIL. CNE/CEB. Parecer 11/2000. Diretrizes Curriculares Nacionais para a Educação de Jovens e Adultos. Relator: Carlos Roberto Jamil Cury, aprovado em 10/05/2000. Diário Oficial da União, MEC/CNE/CEB, Brasília, 9 jun. 2000, Seção 1e, p. 15. Disp.: <http://portal.mec.gov.br/secad/arquivos/pdf/eja/legislacao/parecer_11_2000.pdf>. Acesso: 9 jul. 2013.

; CNE/CP. Resolução 05, de 13 de dezembro de 2005. Institui Diretrizes Curriculares Nacionais para o Curso de Graduação em Pedagogia, licenciatura. Diário Oficial da União, Brasília, 09 dez. 2005, Seção I, p. 24. Disp.: < http://portal.mec.gov.br/seb/arquivos/pdf/res_ceb_05.05\%20_servapoiesc.pdf >. Acesso: 08 out. 2011.

; CNE/CP. Resolução 02/2015. Define as Diretrizes Curriculares Nacionais para a formação inicial em nível superior (cursos de licenciatura, cursos de formação pedagógica para graduados e cursos de segunda licenciatura) e para a formação continuada. Diário Oficial da União, Brasília, 2 jul. 2015, Seção 1, p. 8-12.

; CNE/CP. Parecer n. 02, aprovado em 9 de junho de 2015. Diretrizes Curriculares Nacionais para a Formação Inicial e Continuada dos Profissionais do Magistério da Educação Básica. Diário Oficial da União, Brasília, 25 jun. 2015, Seção 1, p. 13.

FREIRE, Paulo. Pedagogia da autonomia: saberes necessários à prática educativa. São Paulo: Paz e Terra, 1996.

GOHN, Maria da Glória. Movimentos sociais e redes de mobilizações civis no Brasil contemporâneo. 2. ed. Petrópolis: Vozes, 2010a.

Novas teorias dos movimentos sociais. 3. ed. São Paulo: Loyola, 2010 b.

GRAMSCI, Antonio. Os intelectuais e a organização da cultura. São Paulo: Círculo do Livro, s. d.

UNIVERSIDADE FEDERAL DO ESPÍRITO SANTO; CENTRO DE EDUCAÇÃO. Projeto Pedagógico do curso de licenciatura em Pedagogia. Vitória, 2010.

PATUZZO, Krolini Galimberti. O pedagogo no contexto da inclusão escolar: possibilidades de ação na escola comum. 2014. Dissertação (Mestrado) - Programa de Pós-Graduação em Educação, Universidade Federal do Espírito Santo. Vitória, 2014. 


\section{RESUMO}

Busca-se neste artigo refletir sobre a formação inicial de educadores na disciplina Movimentos sociais $e$ educação de jovens e adultos (MSEJA) do Curso de Pedagogia da Universidade Federal do Espírito Santo e suas contribuições para a formação acadêmica e política dos estudantes. A base teórica utilizada integra estudos sobre dimensões conceituais dos movimentos sociais e da EJA, na relação com a práxis na formação de professores. Como pesquisa qualitativa, operamos com a observação participante durante as aulas e a escuta dos estudantes por meio de questionários e entrevistas semiestruturadas. Os resultados indicam a necessidade de ampliar e fortalecer esse debate na formação inicial e o desafio de promover espaços de maior interlocução com os movimentos sociais.

Palavras-chave: Educação de jovens e adultos. Movimentos sociais. Formação de educadores e educadoras.

\section{ADULT EDUCATION SOCIAL MOVEMENTS AND INITIAL EDUCATION OF UNDERGRADUATE PEDAGOGY STUDENTS IN UNIVERSITY}

\section{ABSTRACT}

This paper aims to reflect on the initial education of undergraduate pedagogy students enrolled in the Social Movements and Youth and Adult Education (MSEJA) class at the Federal University of Espírito Santo. It investigates the contributions of the mentioned academic subject towards students political and academic education. The theoretical basis used includes studies on the conceptual dimensions of social movements and adult education, in relation to the teacher education practice. As a qualitative research, the primary means of data collection were in class participant observation and semi-structured questionnaires and interviews applied to the students. The results indicate the need to expand and strengthen this debate in undergraduate teaching courses as well as the challenge of promoting greater dialogue with the social movements.

Keywords: Youth and adult education. Social movements. Teacher education.

Submetido em Jan. 2016 Aprovado em Jun. 2016 